\title{
CLOVES syndrome with thoracic and central phlebectasia: Increased risk of pulmonary embolism
}

\author{
Ahmad I. Alomari, MD, ${ }^{\text {a }}$ Patricia E. Burrows, MD, ${ }^{b}$ Edward Y. Lee, MD, MPH, ${ }^{\mathrm{c}}$ Daniel J. Hedequist, MD, ${ }^{\mathrm{d}}$ \\ John B. Mulliken, MD, ${ }^{e}$ and Steven J. Fishman, MD $^{f}$
}

\begin{abstract}
Objective: CLOVES syndrome (congenital lipomatous overgrowth, vascular malformations, epidermal nevi, and skeletal/scoliosis and spinal abnormalities) is a rare, complex overgrowth syndrome with serious morbidity. In this communication we studied the presence of central and thoracic phlebectasia in patients with CLOVES syndrome and its clinical implications.
\end{abstract}

Methods: We conducted a comprehensive search of our databases at Children's Hospital Boston over the last 10 years (1999-2008) for patients with CLOVES syndrome and central and thoracic phlebectasia. Medical records, clinical photographs, and imaging studies of varying modalities were reviewed.

Results: Review of the clinical data and imaging studies of 12 patients with CLOVES syndrome documented the presence of central and thoracic phlebectasia in 11 patients. Two patients had serious perioperative pulmonary embolism, and 1 died.

Conclusions: Central and thoracic phlebectasia in patients with CLOVES syndrome is common and increases the risk of pulmonary embolism. Aggressive prophylactic measures should be considered before major interventions. (J Thorac Cardiovasc Surg 2010;140:459-63)

There is a well-recognized risk of pulmonary embolism in patients with overgrowth and complex vascular anomalies. Although isolated and simple congenital dilatation of the central or cervical veins (phlebectasia) is generally a benign condition, these vascular anomalies in CLOVES syndrome (congenital lipomatous overgrowth, vascular malformations, epidermal nevi, and skeletal/scoliosis and spinal abnormalities) can cause morbidity and mortality.

\section{MATERIALS AND METHODS}

The Committee on Clinical Investigation of Children's Hospital Boston approved this study. The database of the Vascular Anomalies Center at Children's Hospital Boston was culled for patients with typical features of CLOVES syndrome who also had cross-sectional or angiographic cervicothoracic imaging. Medical records and imaging studies were retrospectively reviewed.

Subjects who were not evaluated at our institution or lacked adequate imaging studies were excluded. Demographic data, characteristics of the lipomatous overgrowth, and vascular, cutaneous, and musculoskeletal features were documented.

\section{RESULTS}

A cohort of 12 patients with the diagnosis of CLOVES syndrome had sufficient cross-sectional or angiographic

\footnotetext{
From the Division of Vascular and Interventional Radiology ${ }^{\mathrm{a}}$ and the Departments of Radiology, ${ }^{\mathrm{c}}$ Orthopedic Surgery, ${ }^{\mathrm{d}}$ Plastic Surgery, ${ }^{\mathrm{e}}$ and Surgery, ${ }^{\mathrm{f}}$ Children's Hospital Boston and Harvard Medical School, Boston, Mass; and the Division of Vascular and Interventional Radiology, ${ }^{\mathrm{b}}$ Texas Children's Hospital, Houston, Tex.

Disclosures: None.

Received for publication Oct 20, 2009; revisions received April 7, 2010; accepted for publication April 25, 2010; available ahead of print May 31, 2010.

Address for reprints: Ahmad I. Alomari, MD, Division of Vascular and Interventional Radiology, Children's Hospital Boston and Harvard Medical School, 300 Longwood Ave, Boston, MA 02115 (E-mail: ahmad.alomari@childrens.harvard.edu). $0022-5223 / \$ 36.00$

Copyright (c) 2010 by The American Association for Thoracic Surgery doi:10.1016/j.jtcvs.2010.04.023
}

studies to permit adequate evaluation of the central veins. Of those, 11 patients ( 7 male and 4 female patients; age range, 5 months to 18 years) had phlebectasia of the thoracic veins, central veins, or both. Table 1 and Figure 1 summarize the major clinical findings.

The distribution of the affected veins in these 11 patients is summarized in Table 2. Phlebectasia of the azygoshemiazygos system was the most common $(9 / 11$; Figure 2 , $A$ ), followed by the innominate $(6 / 11,3$ bilateral; Figure 2 , $B$ ), subclavian $(6 / 12,4$ bilateral; Figure $2, C)$, superior vena caval (SVC; 3/13), lateral thoracic $(2 / 12$; Figure $2, C$ ), axillary (1/12), and jugular (1/12) veins. The inferior vena cava (IVC) demonstrated focal megacava (1/11) and absence of the IVC (because of agenesis or prior thrombosis in $2 / 11$ patients). There were 2 patients with azygos continuation of the IVC, one of whom had an associated right aortic arch.

Two patients with subclavian phlebectasia had a history of symptomatic pulmonary embolism; both episodes occurred intraoperatively, while the patient was in the prone position. The first patient (no. 1 in Tables 1 and 2) was a 16-year-old girl who had undergone resection of a massive posterior thoracic lipomatous mass. During general anesthesia and being positioned for a wounddressing change, she suddenly became cyanotic. She had severe cardiorespiratory and hemodynamic compromise caused by a massive bilateral pulmonary embolism from a thrombus in a markedly ectatic axillary-subclavian vein. Immediate sternotomy and pulmonary thrombectomy followed by placement of an SVC filter. The postoperative period was complicated by major neurologic deficits, infection, and multiorgan failure culminating in death. 


\section{Abbreviations and Acronyms \\ CLOVES = congenital lipomatous overgrowth, vascular malformations, epidermal nevi, and skeletal/scoliosis and spinal abnormalities \\ CT = computed tomography \\ IVC = inferior vena cava \\ SVC = superior vena cava}

complex vascular anomalies with overgrowth has been reported, but pulmonary embolism has not been previously recognized in patients with CLOVES syndrome. Patients with Klippel-Trenaunay syndrome have combined capillary-lymphatic-venous malformations and are at higher risk for thromboembolic events than are those with less extensive, isolated vascular malformations. ${ }^{3}$ The incidence of venous thrombosis and pulmonary embolism in patients with Klippel-Trenaunay syndrome has been reported to be $14 \%$ and $22 \%$, respectively, with more than half of the episodes occurring in the postoperative period. ${ }^{4}$ Pulmonary embolism is the most common cause of premature death in patients with Proteus syndrome, a rare disorder of disproportionate asymmetric overgrowth, cerebriform connective tissue nevi, epidermal nevi, and vascular malformations. ${ }^{5}$ Thromboembolism in patients with Proteus syndrome is analogous to that in CLOVES syndrome; that is, it occurs in the perioperative setting and affects a similar age group. ${ }^{6,7}$

Phlebectasia of the major central veins is a rare congenital anomaly usually affecting the internal jugular vein. ${ }^{8}$ The coexistence of anomalous lymphatic and venous channels can be explained by a common embryonic precursor of these 2 vascular lineages. ${ }^{9,10}$ Joseph and colleagues ${ }^{10}$ reviewed the CT scans of 11 patients who had lymphatic malformation of the mediastinum with variable extension into the neck and axilla. Five of the 11 had gross dilatation of the SVC, and a sixth patient had aneurysmal expansion of the left innominate and jugular veins. Cervical lymphatic malformations can also be associated with intracranial dural venous anomalies, such as persistent falcine sinus, underdeveloped superior sagittal sinus, and prominent occipital sinus. ${ }^{11,12}$

Upper extremity deep venous thrombosis, as occurred in 3 of our patients, accounts for about $14 \%$ of all pulmonary emboli and can be precipitated by vigorous exercise, trauma, or anatomic compression, although in many patients no thrombogenic cause can be identified. ${ }^{13}$ Anticoagulation is

TABLE 1. Summary of the clinical features of 11 patients with CLOVES syndrome and central phlebectasia

\begin{tabular}{|c|c|c|c|c|c|c|c|c|c|c|c|c|}
\hline \multirow[b]{2}{*}{ System } & \multirow[b]{2}{*}{ Feature } & \multicolumn{11}{|c|}{ Patient no. } \\
\hline & & 1 & 2 & 3 & 4 & 5 & 6 & 7 & 8 & 9 & 10 & 11 \\
\hline \multirow[t]{4}{*}{ General } & Age* & $16 \mathrm{y}$ & $3 y$ & $10 \mathrm{mo}$ & $8 \mathrm{y}$ & $5 \mathrm{mo}$ & $18 \mathrm{y}$ & $8 \mathrm{y}$ & $5 \mathrm{mo}$ & $18 \mathrm{y}$ & $11 \mathrm{y}$ & $10 \mathrm{mo}$ \\
\hline & Sex & $\mathrm{F}$ & $\mathrm{F}$ & $\mathrm{F}$ & M & M & $\mathrm{F}$ & M & M & M & M & M \\
\hline & Mosaic/asymmetric & + & + & + & + & + & + & + & + & + & + & + \\
\hline & Family history & - & - & - & - & - & - & - & - & - & - & - \\
\hline Lipomatous overgrowth & Trunk & + & + & + & + & + & + & + & + & + & + & + \\
\hline \multirow[t]{3}{*}{ Vascular } & Lymphatic malformation & + & + & + & + & + & NA & + & + & + & + & + \\
\hline & Capillary malformation & + & + & $\mathrm{R}$ & NA & + & + & + & + & NA & NA & + \\
\hline & Venous malformation & \multicolumn{11}{|c|}{ summarized in table 2} \\
\hline \multirow[t]{5}{*}{ Musculoskeletal } & Limbs: wide hands or feet & + & + & + & NA & + & + & NA & + & + & + & + \\
\hline & Limbs: "sandal-gap"' deformity & - & NA & NA & NA & + & NA & NA & NA & + & + & NA \\
\hline & Limbs: macrodactyly & - & + & + & + & NA & + & + & + & + & NA & NA \\
\hline & Limbs: asymmetry & + & NA & NA & NA & + & + & NA & + & + & + & + \\
\hline & Scoliosis & NA & + & NA & NA & + & + & - & + & + & + & - \\
\hline
\end{tabular}

$N A$, Data not available/not applicable; $R$, reported in the history and not confirmed by the authors. *At the time of the first evaluation at our institution. 

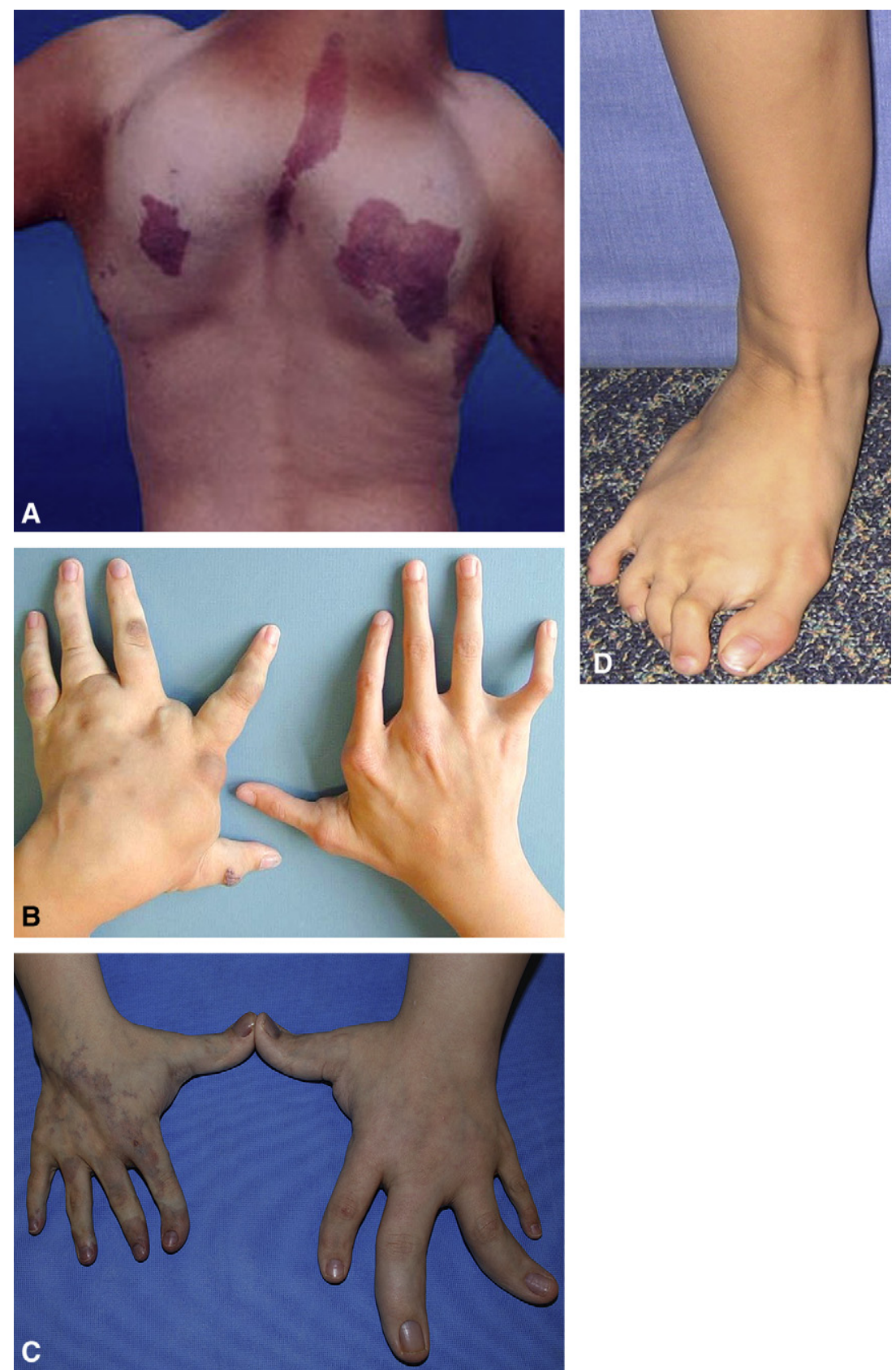

FIGURE 1. Large bilateral truncal fatty masses with bilateral distribution partially covered by capillary malformations (port-wine stain; A). The hands are asymmetrically wide and overgrown with increased interdigital spaces (B) and macrodactyly primarily affecting the left third and fourth fingers (C). The photograph in panel D shows the typical broad feet and "sandal-gap" deformity.

the mainstay of treatment; additional interventions are reserved for selected patients. ${ }^{14}$ In addition, the short-term effectiveness and safety of an SVC filter in the treatment of upper extremity deep venous thrombosis has been well documented. ${ }^{15}$

Thromboembolism in patients with CLOVES syndrome can be explained, at least in part, by stagnant flow in an ectatic thoracic vein, central vein, or both. We recommend contrast-enhanced cross-sectional imaging of the chest and abdomen (with special attention to the venous anatomy) in patients with CLOVES syndrome before any invasive procedure. The venous system of the extremities and chest wall can be reliably examined with ultrasonography or ascending venography.

Venous ectasia, particularly in the neck and upper extremity, is generally believed to be an isolated finding of little, if any, clinical significance. ${ }^{16}$ Nevertheless, 2 patients with CLOVES syndrome in our cohort had serious pulmonary 
TABLE 2. Phlebectasia in 11 patients with CLOVES syndrome

\begin{tabular}{|c|c|c|c|c|c|c|c|c|c|}
\hline No. & SVC & IVC & Innominate & Azygos/hemiazygos & Jugular & Axillary & Subclavian & Lateral thoracic & Azygos continuation \\
\hline 1 & - & - & $\mathrm{R}$ & + & NA & B & B & $\mathrm{B}$ & - \\
\hline 2 & + & NA & $\mathrm{B}$ & + & - & NA & B & - & $*$ \\
\hline 3 & - & - & $\mathrm{B}$ & NA & - & NA & B & NA & NA \\
\hline 4 & - & - & - & + & - & NA & - & - & NA \\
\hline 5 & - & - & - & + & - & - & - & - & - \\
\hline 6 & - & - & - & - & $\mathrm{L}$ & NA & $\mathrm{L}$ & - & - \\
\hline 7 & - & $\dagger$ & - & + & - & - & - & - & - \\
\hline 8 & - & $\ddagger$ & B & + & NA & NA & B & B & + \\
\hline 9 & - & - & $\mathrm{R}^{*}$ & + & - & NA & $\mathrm{R}^{*}$ & - & - \\
\hline 10 & + & $\S$ & - & + & - & NA & - & NA & + \\
\hline 11 & + & - & $\mathrm{R}$ & + & - & NA & - & - & - \\
\hline
\end{tabular}

$S V C$, Superior vena cava; $I V C$, inferior vena cava; $R$, right; $N A$, data not available/not applicable; $B$, bilateral; $L$, left. *Possibly present/suggested on imaging study. $\dagger$ Dilated suprarenal inferior vena cava. $\ddagger$ No iliac vein or inferior vena cava seen (except for intrahepatic inferior vena cava). $\S$ Absent inferior vena cava.

embolism, with 1 fatality; both patients had unusual phlebectasia. The intraoperative prone position in patients with innominate-subclavian phlebectasia is especially dangerous. Thus we propose that phlebectasia is the principal implicated factor predisposing to thrombosis. Sluggish flow within thoracic ectatic veins is likely exacerbated in the prone position because of decreased venous return, dependency, and direct compression. Interestingly, both patients with thromboembolism had an unusual distribution of the ectatic veins involving the axillary-subclavian veins and the lateral thoracic vein. The clinical significance of phlebectasia of the azygos venous system is unclear.
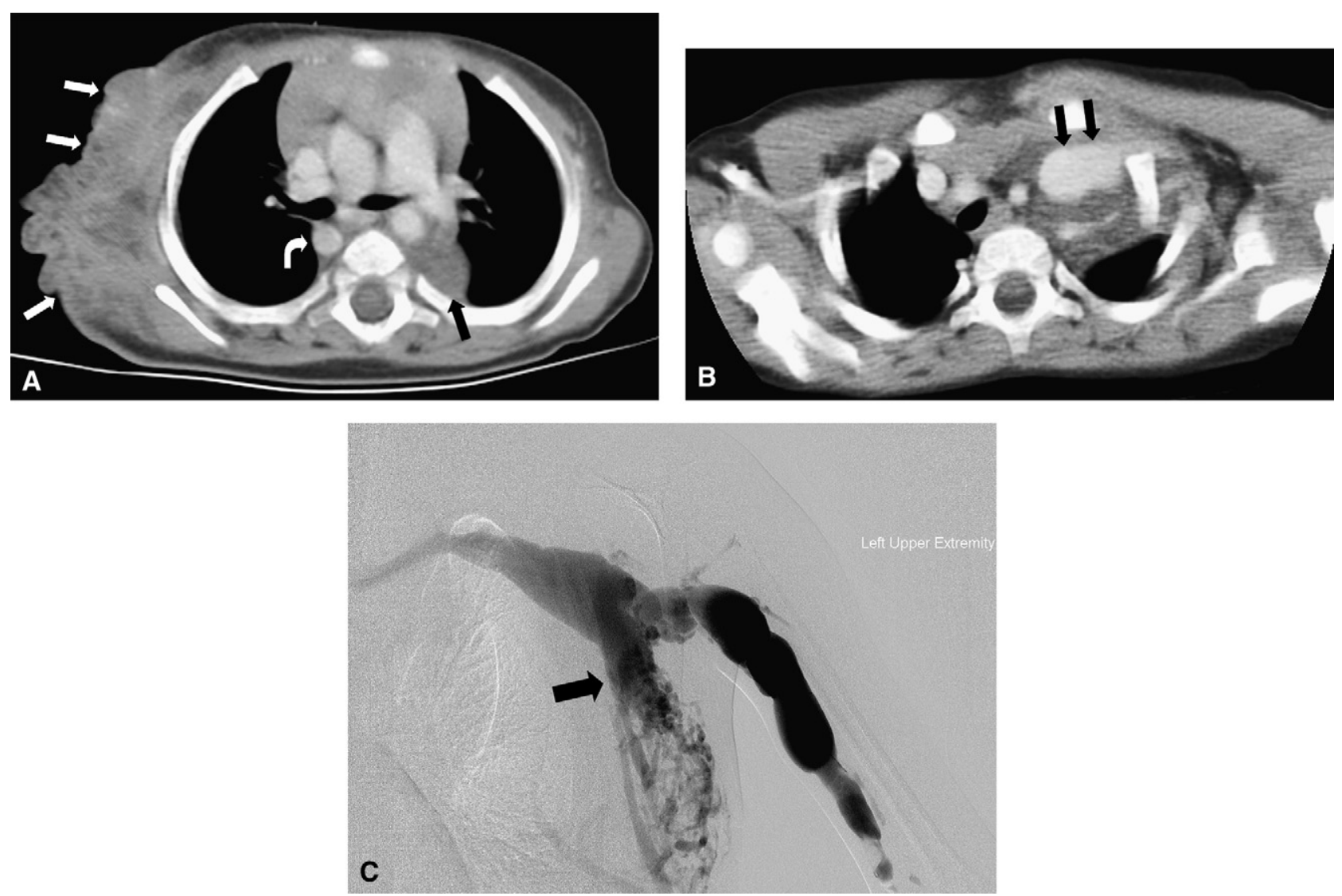

FIGURE 2. A, Enhanced computed tomographic scan through superior mediastinum. The azygos vein is ectatic (curved arrow). Note the overgrowth of the chest wall (white arrow) and posterior mediastinum (black arrow). B. The left innominate vein is markedly dilated (black arrows) and surrounded by mediastinal lymphatic malformation. C, Venogram of the left upper extremity showing marked phlebectasia of the axillary, subclavian, and lateral thoracic veins (arrow) with a relatively normal innominate vein. 
There are 2 limitations in our study: the retrospective design and the small sample. Ascertainment bias could have resulted in overestimation of the frequency and risk of phlebectasia in this cohort of patients with CLOVES syndrome. Further studies are needed to substantiate our findings.

In conclusion, the potentially serious association between phlebectasia and thromboembolism in patients with CLOVES syndrome should alert clinicians to strongly initiate appropriate prophylactic measures, such as anticoagulation and caval filtration, particularly in the perioperative period. Central and thoracic phlebectasia in patients with CLOVES syndrome should be considered one of the few indications for placement of an SVC filter.

We thank Ms Kim Chalache and Ms Cindy Dube for their help in collecting the data and preparing the manuscript.

\section{References}

1. Sapp JC, Turner JT, van de Kamp JM, van Dijk FS, Lowry RB, Biesecker LG. Newly delineated syndrome of congenital lipomatous overgrowth, vascular malformations, and epidermal nevi (CLOVE syndrome) in seven patients. Am J Med Genet. 2007;143A:2944-58.

2. Alomari AI. Characterization of a distinct syndrome that associates complex truncal overgrowth, vascular, and acral anomalies: a descriptive study of 18 cases of CLOVES syndrome. Clin Dysmorphol. 2009;18:1-7.
3. Huiras EE, Barnes CJ, Eichenfield LF, Pelech AN, Drolet BA. Pulmonary throm boembolism associated with Klippel-Trenaunay syndrome. Pediatrics. 2005;116: e596-600

4. Baskerville PA, Ackroyd JS, Lea Thomas M, Browse NL. The Klippel-Trenaunay syndrome: clinical, radiological and haemodynamic features and management. Br J Surg. 1985;72:232-6.

5. Cohen MM Jr. Proteus syndrome: an update. Am J Med Genet C Semin Med Genet. 2005;137C:38-52.

6. Slavotinek AM, Vacha SJ, Peters KF, Biesecker LG. Sudden death caused by pulmonary thromboembolism in Proteus syndrome. Clin Genet. 2000;5: 386-9.

7. Biesecker L. The challenges of Proteus syndrome: diagnosis and management Eur J Hum Genet. 2006;14:1151-7.

8. Siani A, Flaishman I, Schioppa A, Zaccaria A, Baldassarre E. Jugular venous phlebectasia: uncommon in children, anecdotal in adults. Am J Surg. 2008;195:419-20.

9. Makariou E, Pikis A, Harley EH. Cystic hygroma of the neck: association with a growing venous aneurysm. AJNR Am J Neuroradiol. 2003;24:2102-4.

10. Joseph AE, Donaldson JS, Reynolds M. Neck and thorax venous aneurysm: association with cystic hygroma. Radiology. 1989;170:109-12.

11. Gürelik M, Ozüm U, Erdoğan H, Aslan A. Orbital lymphangioma and its association with intracranial venous angioma. Br J Neurosurg. 2004;18:168-70.

12. Tada H, Takanashi J, Barkovich AJ, Kohno Y. Intracranial dural venous anomalies in familial cervical cystic hygroma. Pediatr Neurol. 2005;32:50-2.

13. Linnemann B, Meister F, Schwonberg J, Schindewolf M, Zgouras D, Lindhoff-Last E. Hereditary and acquired thrombophilia in patients with upper extremity deep-vein thrombosis. Results from the MAISTHRO registry. Thromb Haemost. 2008;100:440-6.

14. Lee AY, Ginsberg JS. Venous thrombosis of the upper extremities. Curr Treat Options Cardiovasc Med. 2001;3:207-14.

15. Usoh F, Hingorani A, Ascher E, Shiferson A, Tran V, Mark N, et al. Long-term follow-up for superior vena cava filter placement. Ann Vasc Surg. 2008;23:350-4.

16. Yoon PJ, Messner AH. Lymphatic malformation with internal jugular phlebectasia. Otolaryngol Head Neck Surg. 2001;124:579-80. 